\title{
Hepatitis B: Prevalence and occult infection in HIV-infected patients
}

\author{
Samira Julien Calux ${ }^{[1]}$, Vanessa Cristina Martins Silva ${ }^{[1]}$, Adriana Parise Compri ${ }^{[1]}$, \\ Marcílio Figueiredo Lemos ${ }^{[1]}$, Ana Paula de Torres Santos ${ }^{[2]}$, Isabel Takano Oba ${ }^{[1]}$, \\ Maria Cássia J. Mendes-Correa ${ }^{[3]}$ and Regina Célia Moreira ${ }^{[1]}$
}

[1]. Laboratório de Hepatites Virais, Centro de Virologia, Instituto Adolfo Lutz, São Paulo, SP, Brasil.

[2]. Divisão de Laboratório Central, Hospital das Clínicas, Universidade de São Paulo, São Paulo, SP, Brasil.

[3]. Departamento de Doenças Infecciosas, Universidade de São Paulo, São Paulo, SP, Brasil.

\begin{abstract}
Introduction: HBV and HIV have identical transmission routes. The aim of this study was to determine the prevalence of HBV in HIV patients and to detect the presence of occult HBV infection. Methods: All samples were tested for serology markers and using qPCR. Results: This study included 232 individuals, out of which $36.6 \%$ presented with HBV markers and $11.8 \%$ presented with $\mathrm{HBsAg}$ or HBV-DNA, including 3 patients that showed OBI. Conclusions: We observed a high prevalence of HBV among HIV patients. In addition, the results suggest that OBI can occur in patients with serological profiles that are indicative of past infection. Therefore, the application of molecular tests may enable the identification of infections that are not evident solely based on serology.
\end{abstract}

Keywords: Prevalence. Occult hepatitis B infection. HBV. HIV.

Hepatitis B virus (HBV) infection is a global public health issue. An estimated 240 million people are chronic carriers, and acute or chronic HBV infections result in approximately 887,000 deaths per year. In the Amazon region and southern regions of Eastern and Central Europe, chronic infections are prevalent among the adult populations. Due to vaccination programs in South America and Oceania, the prevalence rates of chronic HBV infection are less than $2 \%$. In Western Europe and North America the burden of chronic infections is less than $1 \%^{1}$. The goal of OMS is to eliminate HBV through efficient vaccination programs by 2030 .

Globally, approximately 35 million people are infected with HIV. The African continent, particularly sub-Saharan Africa, is the most affected region with an average 25.7 million people infected with HIV. Amongthe HIV carriers, at least 7.4\% are co-infected with $\mathrm{HBV}^{2}$.

The high prevalence of co-infection is explained by the similarity in the transmission routes of hepatitis B virus and HIV ${ }^{3}$. The progression of chronic hepatitis to cirrhosis, hepatocellular

\footnotetext{
Corresponding author: Dra Regina Célia Moreira.

e-mail: regina.moreira7@gmail.com

(D) 0000-0002-8208-8776

Received 13 December 2018

Accepted 5 September 2019
}

carcinoma, and terminal stage liver disease is faster in individuals infected with HIV than in those infected with HBV alone. Therefore, co-infection can increase the morbidity and mortality compared with an HBV mono-infection ${ }^{4}$.

The laboratory diagnosis of HBV infection depends on the serological detection of total anti-HBc, HBsAg, and other markers that may be used to monitor the infection and evaluate immune response $^{5}$. In addition, molecular assays are used for diagnosis in children and monitoring of HBV infection.

In some cases of infection, low concentrations (lower than 200 $\mathrm{IU} / \mathrm{ml}$ ) of HBV DNA is detected in the serum or plasma of patients that tested negative for presence of HBsAg. This is a feature of occult Hepatitis B infection (OBI), which is described as the presence of HBV DNA in blood, at undetectable levels of HBsAg (with or without anti-HBc and anti-HBs), outside the pre-seroconversion window period ${ }^{6}$. This condition is reported frequently in HIVinfected patients, particularly among those that are treatment-naïve ${ }^{5}$.

Owing to differences in sensitivity and specificity between different detection methods, the prevalence of OBI is variable worldwide among various categories of individuals ${ }^{6}$. In Northern countries where the prevalence of infection is below $5 \%$, and the prevalence of chronic infection less than $1 \%$, the prevalence of OBI does not exceed $5 \%{ }^{7}$. In contrast, OBI is observed to affect 
4-24\% of the population in India, Taiwan, Japan, and Sardinia. In West Africa, approximately $5 \%$ of total HBV DNA carriers are HBsAg negative ${ }^{8}$.

The aim of this study was to determine the prevalence of HBV and detect presence of OBI, in a group of HIV patients.

This study included HIV-infected patients, receiving follow up care at outpatient service that supports patients living with HIV/AIDS (SEAP) in São Paulo city. Between June 2013 and May 2014, two vials of peripheral blood were collected from each patient. Ethylenediaminetetraacetic acid (EDTA) was added to the samples. The blood samples were tested for the presence or absence of HBsAg, Anti-HBs, and total Anti-HBc antibodies. The tests were performed according to the manufacturer's instructions (DiaSorin; Saluggia-Vercelii, Italy).

All the samples were subjected to HBV quantitative real time polymerase chain reaction (qPCR), according to the manufacturer's instructions (Abbott RealTime HBV, Des Plaines, IL, USA).To eliminate the pre-conversion window period, the PCR positive samples were tested for the presence of Anti-HBc IgM usinga Cobas ${ }^{\circledR}$ Anti-HBc IgM Cobas ${ }^{\circledR}$-Roche Diagnostics kit (Mannhein, Germany).

Blood samples were collected only after the written consent form was signed by the patient. This study was approved by the Ethical Committee in Research from Instituto Adolfo Lutz (CEPIAL\#186.915).

This study enrolled 232 patients. HBV markers, wither in isolation or in association with other markers, were detected in $65.5 \%(152 / 232)$ of the patients.

Hepatitis B was detected in $36.6 \%(85 / 232)$ of samples with exposure markers. Out of these, evidence of chronic infection and previous contact with HBV was indicated in $8.2 \%(7 / 85)$ and $91.8 \%$ (78/85) of the patients, respectively (Table 1).
The viral DNA was detected in six samples, of which two were quantified. HBV DNA was detected in four samples. However, the concentration of HBV DNA was below the limit of quantification (10 IU/ml). The PCR positive samples tested negative for presence of anti-HBc IgM. The absence of serological markers of acute infection and the presence of HBV DNA indicated the presence of OBI in 3 patients (Table 2).

The values of prevalence and co-infection of HBV in HIV-infected patients observed in this study were similar to those reported in the previous studies conducted in Brazil. A study in São Paulo indicated that $38.6 \%$ of patients tested positive for total anti-HBc, and $5.7 \%$ of patients tested positive for HBsAg reagents ${ }^{9}$. In Ribeirão Preto, the overall prevalence of $\mathrm{HBV}$ infection was observed to be $40.9 \%$, with $8.5 \%$ testing positive for $\mathrm{HBsAg}$, $39.7 \%$ testing positive for total anti-HBc, and $8.5 \%$ co-infected $^{10}$. In a study in the Amazon region, the prevalence was $40.2 \%$ for resolved HBV infection, and $6.4 \%$ of patients tested positive for $\mathrm{HBsAg}^{11}$. In the state of Ceará, $23 \%$ of patients were previously exposed to HBV and $3.7 \%$ were co-infected ${ }^{12}$. Recently, in Goiânia, the presence of HBV exposure markers were detected in $33.5 \%$ of the patients, while the HBsAg marker was detected in $3.8 \%$ of patients.

Total anti-HBc was isolated from blood samples of two of these patients, while total anti-HBc associated with anti-HBs was detected in one patient.

These data suggest that OBI can occur in patients with serology suggestive of past $\mathrm{HBV}$ infection or in those presenting serological evidence of viral exposure.

In a study conducted in Nigeria with $188 \mathrm{HIV}$-infected patients, OBI was detected in 21 patients, resulting in a prevalence of $11.2 \%{ }^{13}$. Thesedata corroborate the results of this study.

The impact of OBI in the prognosis of HIV-infected patients requires further investigation. However, evidence indicates that the

TABLE 1: Serological profiles identified in the study group.

\begin{tabular}{|c|c|c|c|c|c|}
\hline \multirow{2}{*}{ Serological profile } & \multicolumn{3}{|c|}{ Serological Markers } & \multirow{2}{*}{\multicolumn{2}{|c|}{ Total of samples (\%) }} \\
\hline & \multirow{2}{*}{$\begin{array}{c}\text { HBsAg } \\
\text { Not reagent }\end{array}$} & \multirow{2}{*}{$\begin{array}{c}\text { Anti-HBs } \\
\text { Not reagent }\end{array}$} & \multirow{2}{*}{$\begin{array}{c}\text { Total Anti-HBc } \\
\text { Reagent }\end{array}$} & & \\
\hline Total Anti-HBc only & & & & 25 & $(10.8)$ \\
\hline Anti-HBc and Anti-HBs & Not reagent & Reagent & Reagent & 53 & $(22.8)$ \\
\hline Anti-HBs only & Not reagent & Reagent & Not reagent & 67 & $(28.9)$ \\
\hline HBsAg and Total Anti-HBc & Reagent & Not reagent & Reagent & 3 & (1.3) \\
\hline HBsAg only & Reagent & Not reagent & Not reagent & 3 & (1.3) \\
\hline All tested markers & Reagent & Reagent & Reagent & 1 & $(0.4)$ \\
\hline No markers & Not reagent & Not reagent & Not reagent & 80 & (34.5) \\
\hline Total & & & & 232 & $(100.0)$ \\
\hline
\end{tabular}


TABLE 2: Samples with detected HBV-DNA.

Sample ID

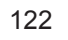

112

105

185

167

187
HBV-DNA (UI/mL)

$<10$

462

$<10$

30

$<10$

$<10$
Serological Group

Presence of $\left.\mathrm{OB}\right|^{*}$

*Occult hepatitis B infection.

presence of HBV DNA may be a risk factor in the progression of liver disease ${ }^{5,8}$. A research group in Italy monitored 86 HIV-infected patients for at least 6 months, out of which 17 patients presented with OBI. Moreover, acute exacerbation of hepatitis B occurred in $28(32.5 \%)$ patients during the follow-up. This event was more frequently observed in 17 HBV DNA-positive patients than in the 69 HBV DNA-negative individuals. The authors suggest that OBI may be associated with a deteriorating liver disease in HIV patients ${ }^{14}$.

Results indicated a high prevalence of hepatitis B among HIVinfected patients. In addition, the results suggest that occult hepatitis $B$ infection can occur in patients with serological profiles indicative of past infection.

\section{ACKNOWLEDGMENTS}

We are grateful to the SEAP team for their assistance and excellent work in the execution of this research.

\section{AUTHOR'S CONTRIBUTION}

RCM: guidance, Project design, article's composing; SJC: patients interview, reasearch development, assay's execution, analysis of medical records, master thesis and article's composing; VCMS: patients interview, analysis of medical records, online database analyses; APC: assay's execution, data analyses, laboratory supervision; MFL: database administrator, data analyses; MCJMC: patients responsable doctor, clinical patients follow up; ITO: assay's execution, laboratory supervision; APTS: assay's execution, data analyses.

\section{CONFLICT OF INTEREST}

The authors declare that there is no conflict of interest.

\section{FINANCIAL SUPPORT}

This work was supported by Coordenação de Aperfeiçoamento de Pessoal de Nível Superior (CAPES).

\section{REFERENCES}

1. World Health Organization (WHO). Fact Sheet 204 [Internet]. 2018. Available from: http://www.who.int/mediacentre/factsheets/fs204/en/ index.html Accessed on: 17.Oct.2018.
2. World Health Organization (WHO). HIV and hepatitis co-infections [Internet]. 2018. Available from: http://www.who.int/hiv/topics/ hepatitis/hepatitisinfo/en/. Accessed on: 17.Oct.2018.

3. Li Y, Wang H, Li T. Hepatitis B virus/human immunodeficiency virus coinfection: interaction among human immunodeficiency virus infection, chronic hepatitis B virus infection, and host immunity. Chin Med J 2012; 125(13):2371-7.

4. Thio C, Smeaton L, Saulynas M, Hwang H, Saravan S, Kulkarni S, et al.Characterization of HIV-HBV co-infection in a multi-national HIV infected cohort. AIDS. 2013;27(2):191-201.

5. Souza M, Passos A, Machado A, Figueiredo J, Esmeraldino L. HIV and hepatitis B virus co-infection: prevalence and risk factors. Rev Soc Bras Med Trop. 2004;37(5):391-5.

6. Raimondo G, Caccamo G, Filomia R, Pollicino T. Occult HBV infection. Semin Immunopatho. 2013;35(1):39-52.

7. Kleinman SH, Kuhns MC, Todd DS, Glynn SA, McNamara A, DiMarco A, et al. Frequency of HBV DNA detection in US blood donors testing positive for anti-HBc: implications for transfusion transmission and donor screening. Transfusion 2003;43(6):696-704.

8. Allain JP. Occult hepatitis B virus infection. Transfus Clin Biol 2004; 11:18-25.

9. Mendes-Corrêa M, Barone A, Cavalheiro ND, Tengan F, Guastini C. Prevalence of hepatitis B and C in the sera of patients with HIV infection in São Paulo, Brazil. Rev Inst Med Trop São Paulo. 2000;42(2):81-5.

10. Tavora L, Hyppolito E, Cruz J, Portela N, Pereira S, Veras C. Hepatitis $\mathrm{B}, \mathrm{C}$ and HIV co-infections seroprevalence in a northeast Brazilian center. Arq Gastroenterol. 2013;50(4):277-80.

11. Braga W, da Costa Castilho M, dos Santos I, Moura M, Segurado A. Low prevalence of hepatitis B virus, hepatitis D virus and hepatitis C virus among patients with human immunodeficiency virus or acquired immunodeficiency syndrome in the Brazilian Amazon basin. Rev Soc Bras Med Trop. 2006;39(6):519-22.

12. Brandão N, Pfrimer I, Martelli C, Turchi M. Prevalence of hepatitis $\mathrm{B}$ and $\mathrm{C}$ infection and associated factors in people living with HIV in Midwestern Brazil. Braz J Infect Dis. 2015;19(4):426-30.

13. Opaleye O, Olureme A, Atiba A, Adewumi MO, Mabayoje O, Donbraye E, et al. Occult hepatits B vírusinfection among HIV positive patients in Nigeria. J Trop Med. 2014;2014:1-5.

14. Di Lello F, Macias J, Cifuentes C, Vargas J, Palomares J, Pineda J. Low prevalence of occult HBV infection among HIV-infected patients in Southern Spain. Enferm Infecc Microbiol Clin. 2012; 30(6):312-4. 